\title{
The International Connection
}

\author{
C.C. Chancey, Editor \\ American Journal of Undergraduate Research \\ University of Northern lowa \\ Cedar Falls, lowa 50614-0150 USA
}

This issue begins AJUR's second year of activity, and-with one year's legs to stand on-the world seems a big place. Much of the world is terra incognita for this journal, though not for want of intent to explore.

An important part of this journal's mission is to foster connections among undergraduate scientists, mathematicians, and engineers in all parts of the world. But in saying this is important, we should not mistake how hard a goal it is to make real. Science is an international endeavor done by an increasingly international body of researchers, but many of the resources for doing science remain in the developed countries. Students in developing countries often do scientific research under burdens that can only engender admiration when the research is done well.

Of course, these are conditions that many of us know-again since the research collective is so international in its body scientific. What can AJUR realistically do to improve the situation?

- AJUR can highlight good undergraduate research, wherever it occurs. It is surely useful for beginning researchers to see what other undergraduates are researching in other countries. And a spotlight on student research at any university, wherever the location, is positive notoriety.

- $\quad$ AJUR can help undergraduate researchers outside the US see the American college system for what it is: very large, highly distributed in locale, and quite variegated in educational emphasis. The variety of liberal arts colleges where good undergraduate science is done is remarkable, and public universities and colleges are equally engaged. American under-graduate research shines from these institutions at least as well as from the large research-intensive universities that are more familiar, in name at least, to those outside the US.

- $\quad$ AJUR can provide undergraduate researchers, both inside and outside the US, with a degree of validation that only comes with dispassionate reviews and open publication. This may be more important to researchers outside the developed world where research accomplishments are harder fought.

This issue brings the second paper that AJUR has published from a student outside the US. In fact, it is the second paper from this journal's diligent senior international editor, Mr. Bamidele Oluwade. This research paper comes from Ladoke Akintola University of Technology, or LAUTECH, as it's abbreviated locally. LAUTECH is a leading state university in Nigeria, with a respected faculty and industrious students. Yet, political and economic circumstances are hard. Rising tuition costs and a just-ended four-month strike by LAUTECH lecturers give an indication of the difficulties that science students and their research mentors face in doing research in Ogbomoso, Nigeria.

The task is great but the responsibility that each of us has for making science, mathematics, engineering, and technology as truly international as possible should be stimulus enough. If you would like to help AJUR make its way in this regard, send the journal an e-mail [c.chancey @uni.edu]. The cost of helping AJUR help undergraduate researchers in developing and under-developed countries is not large but there are costs. If you are able to make a donation or buy a subscription on behalf of a foreign university library, send an e-mail-and consider sending a check [payable to AJUR]. It's a great investment in the future. 